\title{
Upper Arctic Ocean water masses harbor distinct communities of heterotrophic flagellates
}

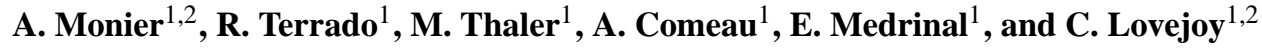 \\ ${ }^{1}$ Département de Biologie, Institut de Biologie Intégrative et des Systèmes (IBIS) and Québec-Océan, Université Laval, \\ Québec, QC, Canada \\ ${ }^{2}$ Takuvik Joint International Laboratory, Université Laval (Canada) - CNRS UMI3376 (France), Québec, QC, Canada
}

Correspondence to: A. Monier (adam.monier@gmail.com) and C. Lovejoy (connie.lovejoy@bio.ulaval.ca)

Received: 30 December 2012 - Published in Biogeosciences Discuss.: 25 February 2013

Revised: 16 May 2013 - Accepted: 20 May 2013 - Published: 27 June 2013

\begin{abstract}
The ubiquity of heterotrophic flagellates (HFL) in marine waters has been recognized for several decades, but the phylogenetic diversity of these small (ca. $0.8-20 \mu \mathrm{m}$ cell diameter), mostly phagotrophic protists in the upper pelagic zone of the ocean is underappreciated. Community composition of microbes, including HFL, is the result of past and current environmental selection, and different taxa may be indicative of food webs that cycle carbon and energy very differently. While all oceanic water columns can be density stratified due to the temperature and salinity characteristics of different water masses, the Arctic Ocean is particularly well stratified, with nutrients often limiting in surface waters and most photosynthetic biomass confined to a subsurface chlorophyll maximum layer, where light and nutrients are both available. This physically well-characterized system provided an opportunity to explore the community diversity of HFL from different water masses within the water column. We used high-throughput DNA sequencing techniques as a rapid means of surveying the diversity of HFL communities in the southern Beaufort Sea (Canada), targeting the surface, the subsurface chlorophyll maximum layer (SCM) and just below the SCM. In addition to identifying major clades and their distribution, we explored the micro-diversity within the globally significant but uncultivated clade of marine stramenopiles (MAST-1) to examine the possibility of niche differentiation within the stratified water column. Our results strongly suggested that HFL community composition was determined by water mass rather than geographical location across the Beaufort Sea. Future work should focus on the biogeochemical and ecological repercussions of different HFL communities in the face of climate-driven changes to the physical structure of the Arctic Ocean.
\end{abstract}

\section{Introduction}

Small phagotrophic protists, often referred to as heterotrophic flagellates (HFL), are ubiquitous and can account for a significant proportion of the microbial eukaryotic biomass in the marine pelagic zone, including in the Arctic Ocean (Sherr and Sherr, 2009). HFL are the defining feature of microbial food webs and impact the global carbon cycle by grazing bacteria that take up organic carbon, thus recycling carbon in the water column and restraining carbon burial to the deep sea (Azam and Malfatti, 2007). As well, HFL are grazed by zooplankton, channeling carbon and energy to higher food webs (Jürgens and Massana, 2008). However, unlike large phytoplankton, most HFL lack easily preserved and readily identifiable morphological characters, and potential taxonomic and functional diversity of HFL is rarely considered. Indeed, earlier studies focused on HFL as the functional group that grazed on bacteria (Sherr and Sherr, 1994), and as pointed out by Forest et al. (2012), biogeochemical models often place them into a single functional guild. However, the single functional grouping is questionable because molecular techniques have revealed that representatives of HFL are found across nearly the entire spectrum of eukaryotic diversity (Massana, 2011). In addition, HFL communities are rarely dominated by a single species or species complex (Lovejoy et al., 2006; Massana et al., 2004), suggesting that taxa are sensitive indicators of external environmental forces (Jones and Lennon, 2010) and that different taxa may be indicative of food webs that cycle carbon and energy very differently. Alternatively, if taxa occur randomly, grouping them as a single guild may be sufficient for conceptual and numeric modeling applications. 
Table 1. Metadata for the Beaufort Sea stations and depths from which eukaryotic microbial communities were sampled (Table S1 lists additional metadata).

\begin{tabular}{|c|c|c|c|c|c|c|c|c|c|}
\hline Station & $\begin{array}{l}\text { Depth } \\
\text { Category }\end{array}$ & $\begin{array}{l}\text { Date } \\
\left(\mathrm{d} \mathrm{m}^{-1} \mathrm{yr}^{-1}\right)\end{array}$ & $\begin{array}{l}\text { Latitude, } \\
\text { Longitude }\end{array}$ & $\begin{array}{r}\text { Depth } \\
(\mathrm{m})\end{array}$ & $\begin{array}{r}T \\
\left({ }^{\circ} \mathrm{C}\right)\end{array}$ & $\begin{array}{r}\text { Salinity } \\
\text { (PSU) }\end{array}$ & $\begin{array}{l}\text { Nitrate } \\
\text { (ISUS) }\end{array}$ & $\begin{array}{l}\text { Fluo } \\
\text { (RU) }\end{array}$ & $\begin{array}{r}\text { PAR } \\
\left(\mu \mathrm{Em} \mathrm{m}^{-2}\right. \\
\left.\mathrm{s}^{-1}\right)\end{array}$ \\
\hline 430 & Surface & $18 / 08 / 09$ & $71.13^{\circ} \mathrm{N}, 136.42^{\circ} \mathrm{W}$ & 3 & -0.8 & 25.93 & 0.35 & 0.04 & 64.42 \\
\hline 430 & $\operatorname{SCM} a$ & $18 / 08 / 09$ & $71.13^{\circ} \mathrm{N}, 136.42^{\circ} \mathrm{W}$ & 55 & -0.94 & 31.11 & 0.73 & 0.33 & 2.44 \\
\hline 430 & SCM & $18 / 08 / 09$ & $71.13^{\circ} \mathrm{N}, 136.42^{\circ} \mathrm{W}$ & 65 & -1.04 & 31.63 & 4.31 & 1.1 & 1.24 \\
\hline 430 & $\mathrm{SCM} b$ & $18 / 08 / 09$ & $71.13^{\circ} \mathrm{N}, 136.42^{\circ} \mathrm{W}$ & 80 & -1.25 & 32.07 & 11.11 & 0.27 & 0.41 \\
\hline 460 & Surface & $19 / 08 / 09$ & $70.40^{\circ} \mathrm{N}, 136.03^{\circ} \mathrm{W}$ & 4 & 0.07 & 25.38 & 0.79 & 0.09 & 20.75 \\
\hline 460 & $\operatorname{SCM} a$ & $19 / 08 / 09$ & $70.40^{\circ} \mathrm{N}, 136.03^{\circ} \mathrm{W}$ & 45 & -1.21 & 30.61 & 1.36 & 0.1 & 1.98 \\
\hline 460 & SCM & $19 / 08 / 09$ & $70.40^{\circ} \mathrm{N}, 136.03^{\circ} \mathrm{W}$ & 56 & -1.03 & 31.14 & 1.78 & 1.28 & 1.14 \\
\hline 460 & $\mathrm{SCM} b$ & $19 / 08 / 09$ & $70.40^{\circ} \mathrm{N}, 136.03^{\circ} \mathrm{W}$ & 80 & -1.23 & 32.07 & 10.43 & 0.29 & 0.21 \\
\hline 540 & Surface & $17 / 08 / 09$ & $70.45^{\circ} \mathrm{N}, 137.53^{\circ} \mathrm{W}$ & 3 & -0.61 & 26.24 & 0.66 & 0.04 & 95.91 \\
\hline 540 & $\operatorname{SCM} a$ & $17 / 08 / 09$ & $70.45^{\circ} \mathrm{N}, 137.53^{\circ} \mathrm{W}$ & 50 & -0.93 & 30.8 & 0.75 & 0.13 & 5.36 \\
\hline 540 & SCM & $17 / 08 / 09$ & $70.45^{\circ} \mathrm{N}, 137.53^{\circ} \mathrm{W}$ & 70 & -1.12 & 31.7 & 4.33 & 0.55 & 1.79 \\
\hline 540 & $\mathrm{SCM} b$ & $17 / 08 / 09$ & $70.45^{\circ} \mathrm{N}, 137.53^{\circ} \mathrm{W}$ & 85 & -1.3 & 32.15 & 10.18 & 0.2 & 0.67 \\
\hline 760 & Surface & $12 / 08 / 09$ & $70.33^{\circ} \mathrm{N}, 140.47^{\circ} \mathrm{W}$ & 3 & 0.51 & 22.45 & 1.44 & 0.09 & 69.71 \\
\hline 760 & $\operatorname{SCM} a$ & $12 / 08 / 09$ & $70.33^{\circ} \mathrm{N}, 140.47^{\circ} \mathrm{W}$ & 50 & -1.1 & 30.31 & 0.99 & 0.11 & 3.45 \\
\hline 760 & SCM & $12 / 08 / 09$ & $70.33^{\circ} \mathrm{N}, 140.47^{\circ} \mathrm{W}$ & 70 & -1.09 & 31.4 & 2.52 & 0.48 & 1.19 \\
\hline 760 & $\mathrm{SCM} b$ & $12 / 08 / 09$ & $70.33^{\circ} \mathrm{N}, 140.47^{\circ} \mathrm{W}$ & 90 & -1.26 & 32.06 & 9.81 & 0.17 & 0.34 \\
\hline
\end{tabular}

The Arctic Ocean is considered more quiescent than other oceans because of extensive ice cover and strong salinitystratification (Rainville et al., 2011). This persistent stratification means that, for most of the Arctic Ocean and surrounding seas, the euphotic zone is nutrient limited, and that much of the productivity takes place within a subsurface chlorophyll maximum (SCM) layer where inorganic nutrients are available and irradiance levels are sufficient for photosynthesis by eukaryotic phytoplankton (Lovejoy et al., 2007; Martin et al., 2010). Given the recent changes in the hydrological regime of the Arctic Ocean (Jackson et al., 2012; Tsubouchi et al., 2012), identifying characteristic taxa that occur in different water masses and depths will be crucial for predicting the consequences of such changes on carbon and energy cycling. Sequence-based 18S rRNA gene surveys enable identifications and comparisons of small eukaryote distributions in marine environments, providing a tool for investigating diversity and distribution of taxa in pelagic systems (Massana et al., 2006). To date, environmental $18 \mathrm{~S}$ rRNA gene surveys in the Arctic Ocean have focused on surface or SCM (Comeau et al., 2011) water masses, but rarely both or over synoptic scales; no studies have yet systematically addressed the vertical distribution of microbial eukaryotes inhabiting waters immediately below the SCM, that is, outside the zone of active photosynthesis.

To test whether the HFL communities can indeed be considered a single guild in the upper water column, or if they reflect a potential functional partitioning, we targeted three distinct water masses in the upper Beaufort Sea water column and hypothesized that HFL would be sensitive indicators of their vertically structured environment. Microbial eukaryotes were surveyed by way of high-throughput "tag pyrosequencing" (Sogin et al., 2006) targeting $\sim 400$ nucleotides within the V4 hyper-variable region of the 18S rRNA gene (Comeau et al., 2011). Using this molecular taxonomic approach, our goal was twofold. First, by identifying the major HFL that live in surface, SCM and below-SCM water masses, we tested whether or not these communities were distinct from each other. Our second objective was to determine whether the short reads covering this region of the 18S rRNA gene contain sufficient phylogenetic signal to explore diversity at high resolution. To examine the possibility of niche differentiation, we analyzed the micro-diversity of a widespread, but as yet uncultivated, clade of heterotrophic marine stramenopiles known as MAST-1 (Massana et al., 2006). We chose MAST-1 because they are likely very specious, and based on comparable similarity at the level of 18S rRNA genes in the clade, they have undergone recent rapid radiation with the potential for ecological specialization (e.g., Hawlitschek et al., 2012).

\section{Material and methods}

To study Arctic HFL assemblages, we collected 3-0.2 $\mu \mathrm{m}$ plankton in the Beaufort Sea in August 2009 aboard the CCGS Amundsen as part of the French-Canadian International Polar Year Program Malina. Specifically, four stations were sampled over one week (Fig. 1a; Table 1; Table S1); three of these stations were east of the Mackenzie Canyon (stations 430, 460 and 540) and one was west of the canyon (station 760). Conductivity, temperature and depth (CTD) profiles were taken using a Sea-Bird SBE-911 mounted on 

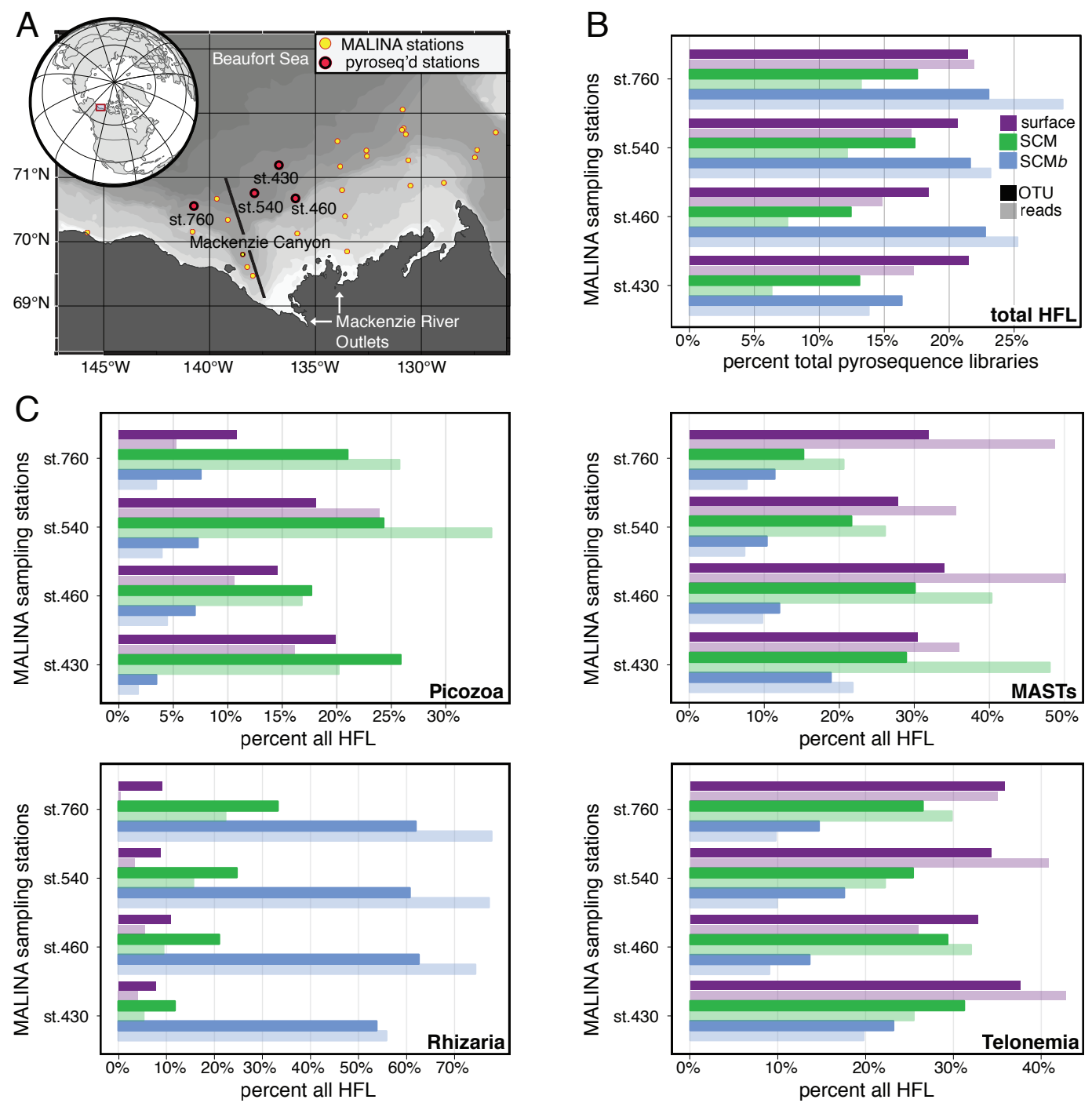

Fig. 1. (A) Beaufort Sea stations sampled during leg 2B of the Malina cruise (August 2009). (B) Overall distributions of HFL reads and OTUs (clustered at $\geq 98 \%$ sequence identity) of sequenced Beaufort Sea microbial eukaryotic communities. Purple, green and blue bars represent surface, SCM and SCM $b$ depths, respectively. Solid and transparent color bars represent OTU and read distributions, respectively. (C) OTU and read distributions of main HFL taxonomic groups across Beaufort Sea samples.

a rosette system which was also fitted with fluorometer (SeaPoint) and in situ optical nitrate probe (Satlantic MBARIISUS). Samples for community analysis were selected on the downward cast from the fluorescence profiles to determine the depth of the SCM. To investigate the vertical structure of HFL communities, we sampled four depths at each station: surface Arctic mixed layer, just above the SCM, the SCM and waters immediately below the SCM where the fluorescence signal had disappeared (these are referred to here as surface, $\mathrm{SCM} a, \mathrm{SCM}$ and $\mathrm{SCM} b$, respectively). Water samples for DNA were collected from 12L Niskin type bottles closed on the upward cast. Six liters of water were sequentially filtered through $3 \mu \mathrm{m}$ pore size, $47 \mathrm{~mm}$-diameter polycarbonate filters and then $0.2 \mu \mathrm{m}$ Sterivex filter units (Millipore) as described earlier (Galand et al., 2009a; Lovejoy and Potvin, 2011). The Sterivex units were stored at $-80^{\circ} \mathrm{C}$ with buffer (1.8 $\mathrm{mL}$ of $40 \mathrm{mmol} \mathrm{L}^{-1}$ EDTA; $50 \mathrm{mmol} \mathrm{L}^{-1}$ Tris $\mathrm{pH}=8.3$; $0.75 \mathrm{~mol} \mathrm{~L}^{-1}$ sucrose).

For this study, DNA was extracted from cells collected on the Sterivex units with an aim to enrich the sample with smaller plankton (Terrado et al., 2011). Extracted DNA was amplified using 18S rRNA gene V4-region-specific 454 primers as described in Comeau et al. (2011). Primers for individual samples included a Roche multiplex identifier sequence, which enabled pooling of amplicons from all samples in equal quantities. The pooled samples were run on 1/4 plate, on the Roche 454 GS-FLX Titanium platform at the IBIS/Université Laval Plateforme d'Analyses 

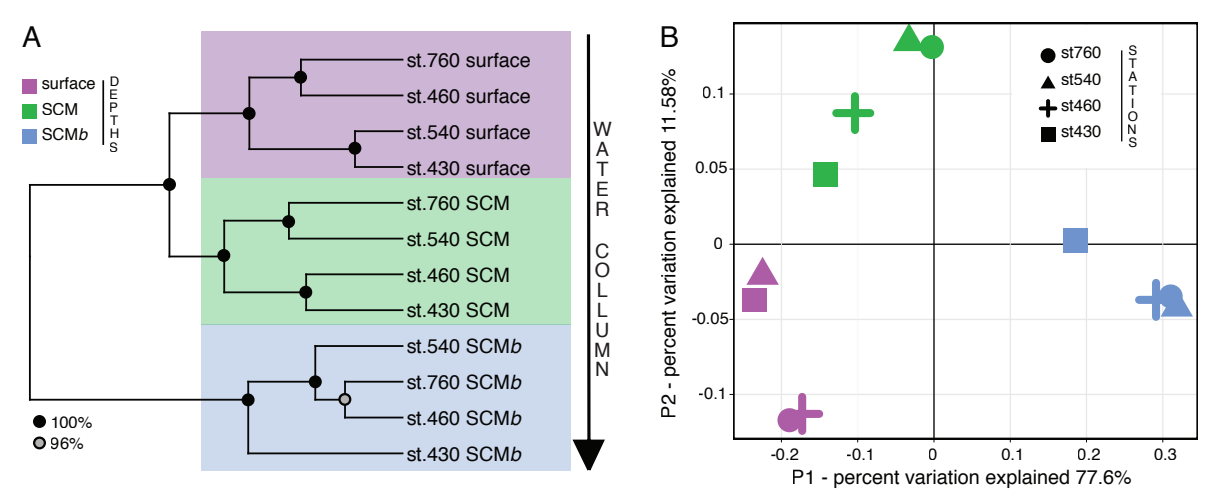

Fig. 2. (A) Weighted Unifrac cluster analysis of HFL OTUs (clustered at $\geq 98 \%$ sequence identity). OTU relative abundances were normalized across samples. Clustering statistical supports were computed using 100 jackknife replicates. (B) Corresponding principal coordinate analysis (PCoA) using UniFrac weighted distance metric.

Génomiques. The raw reads have been deposited in the NCBI Sequence Read Archive (SRA) as accession SRA063446 (BioProject: PRJNA202104).

Raw reads were quality controlled and chimeras were detected using UCHIME (Edgar et al., 2011); in addition, reads smaller than 300 nucleotides were discarded from the study. Retained reads were aligned using the Silva eukaryotic alignment (Pruesse et al., 2007) as a template and clustered into operational taxonomic units (OTUs) at at the $\geq 98 \%$ similarity level, using Mothur v1.21.1 (Schloss et al., 2009) as described in Comeau et al. (2011). We discarded singleton OTUs from our subsequent analyses (note that we used reads from two additional Beaufort Sea stations to cluster OTUs and to identify singleton OTUs in order to maximize the number of sequences kept; these additional station sequences were removed and will be treated in a separate study). Resulting OTUs were taxonomically identified using Mothur and a user-designed taxonomy outline and reference sequence database (Comeau et al., 2011), trimmed only to the V4 region. After preliminary taxonomic analyses, we merged the reads from both SCM $a$ and SCM samples because the communities were globally similar in terms of composition for those two depths at all stations; in addition, a detrended correspondence analysis using untransformed values of temperature, salinity, nitrate concentration, fluorescence photosynthetically active radiation (PAR) also grouped the SCM $a$ and SCM together (not shown). Sequences classified as known HFL based primarily on Adl et al. (2012) were selected, and all other sequences were discarded from this study. Specifically, we targeted sequences classified as Amoebozoa, Apusozoa, Centroheliozoa, choanoflagellates, Katablepharidophyta, MASTs, Picozoa, Rhizaria or Telonemia; sequences classified as Alveolata, Chlorophyta, Cryptophyta, Euglenozoa, Glaucocystophyceae, Haptophyceae, Heterolobosea, Jakobida, Malawimonadidae, Rhodophyta or non-MAST stramenopiles were filtered out from the present analysis and will be dealt with in a subsequent study. In addition, we removed all sequences classified as belonging to multicellular organisms, that is, Fungi, Metazoa and Streptophyta lineages.

Distribution and statistical analyses were computed in the $\mathrm{R}$ environment v2.12.1 (www.r-project.org), and plots were generated using the R package ggplot2 (Wickham, 2009). All statistical analyses were performed on subsampled read and OTU datasets (sizes: 2900 and 800, respectively).

We used the Fast UniFrac web server (Hamady et al., 2010) to compute all UniFrac distances between sampled HFL communities and generate corresponding UPGMA clusters and principal coordinate analysis (PCoA) plots. UniFrac distances were calculated using a large-scale phylogenetic tree based on the Mothur/Silva alignment of all heterotroph-like reads and reconstructed using FastTree v2.1 (Price et al., 2010) in "accurate mode" (-mlacc 2-slownni) with the general time reversible (GTR) model and pseudocounts. Corrected $p$ values from UniFrac significance tests were computed using normalized UniFrac weighted distances with 500 permutations.

To generate the MAST-1 reference phylogenetic tree, we first retrieved "long" reference 18S rRNA gene sequences (i.e., originating from Sanger sequencing) from Genbank based on published MAST phylogenies (e.g., Lin et al., 2012). We also added putative MAST-1 18S rRNA gene sequences recently submitted to Genbank (as of June 2012) identified through MAST-1-specific BLASTn searches (Altschul et al., 1997) as well as a group of most immediate outgroup sequences. These reference and outgroup $18 \mathrm{~S}$ rRNA gene sequences and the reads classified as MAST1 (total 970 sequences) were then aligned with Mothur using the Silva eukaryotic alignment as a template. The resulting alignment was inspected and trimmed to give uniform $5^{\prime} / 3^{\prime}$ using Seaview v4 (Gouy et al., 2010) and was eventually composed of 650 positions. We first built a MAST1 reference phylogenetic tree using an alignment of nearly full-length published 18S rRNA gene sequences originating from Sanger clone sequencing. Aligned reference sequences were extracted and used to reconstruct the reference MAST-1 
phylogenetic trees with RAxML v7.2.8 (Stamatakis, 2006). Specifically, we used GTR model and gamma rate variation among sites, and the best phylogenetic tree was identified from 100 maximum-likelihood reconstruction runs; node statistical supports of this MAST-1 reference tree were computed from 1000 rapid bootstrap trees. Reads classified as MAST-1 were placed onto the reference phylogenetic tree using the RAxML evolutionary placement algorithm (Berger and Stamatakis, 2011); only common alignment positions between MAST-1 reference sequences and reads were used for phylogenetic placements.

\section{Results}

\subsection{Environmental characteristics and general results}

Although all sampled stations were close to the main discharge of the Mackenzie River, we found no freshwater or river signal in CTD measurements (Fig. S1; Table 1). Temperature and salinity (TS) properties of the four depths indicated that the samples fell within three water masses previously identified in the Beaufort Sea (Carmack and Macdonald, 2002; McLaughlin et al., 2005) with the surface samples taken from the Arctic mixed layer (AML), the SCM samples taken from Bering Sea summer water (BSSW) and the SCM $b$ from Bering Sea winter water (BSWW).

After sequence quality filtering (Table S2) and clustering ( $\geq 98 \%$ identity), OTUs were taxonomically classified; we then targeted and kept only sequences assigned to known HFL taxonomic groups. The final dataset of 12 samples consisted of four stations spanning three water masses each.

Based on taxonomic prediction outputs, HFL sequences represented $14.6 \%$ of all sequences (8697 out of a total of 59409 sequences; Table S3). HFL sequences (Fig. 1b) ranged from $7.5 \%$ of all sequences (station $460 \mathrm{SCM}$ ) to $28.7 \%$ (station $760 \mathrm{SCM} b$ ). The HFL sequences were grouped as 784 distinct OTUs, representing $19.35 \%$ of total OTUs. At the higher taxonomic group level (Adl et al., 2012), the HFL OTUs were classified (Fig. 1c; Table S3) as MASTs (156 OTUs from 2390 reads), which are paraphyletic, mostly uncultivated protists assumed to be phagotrophic (Massana et al 2004); Picozoa (115/1198), a recently described phylum (Seenivasan et al., 2013) previously known as "pico biliphytes"; choanoflagellates (37/219); Rhizaria (296/2758); and Telonemia (177/2128). We found a negligible number of sequences classified as Centroheliozoa and Katablepharidophyta ( 2 and 3 sequences, respectively) and none classified as Apusozoa or Amoebozoa.

\subsection{Vertical HFL taxonomic distributions}

The proportion of HFL reads to total reads (a proxy for relative abundance) as well as the number of HFL OTUs (a measure of taxonomic diversity) did not vary significantly by station (Fig. 1b; Table S3). In contrast, there were significant differences with relative depth. The SCM samples were consistently poorer in both HFL reads and HFL OTUs compared to samples from the surface (ANOVA and Tukey's HSD test; reads: $p=0.09$; OTUs: $p<0.05)$ and $\operatorname{SCM} b(p \leq 0.01$; $p<0.05$ ). We caution here that this is likely due to an increase in phytoplankton species in SCM samples occupying "sequencing space". SCM $b$ samples were populated with more HFL reads and OTUs compared to other samples, consistent with HFL being favored in the deeper waters. The only exception was station 430 for which both HFL OTUs and reads were more abundant in surface waters.

We found no significant differences in distributions for the HFL taxonomic groups among stations, but differences across depth category were marked. Specific major groups accounted for many of these differences. For example, overall diversity of Picozoa OTUs was greater in the surface and SCM samples than in deeper waters $(p<0.05$; Fig. 1c). In addition, the proportion of Picozoa reads tended to be greater in $\mathrm{SCM}$ than $\mathrm{SCM} b$ waters, but this was not significant ( $p=0.08)$. Surface waters were significantly richer in OTUs and reads classified as MASTs $(p<0.001)$ and Telonemia $(p<0.005)$. Although not significant, choanoflagellate sequences were consistently more abundant in surface samples (Fig. S2). For all SCM $b$ samples, HFL communities were overwhelmingly dominated by Rhizaria $(p<0.001)$, which represented more than half of all HFL OTUs and reads.

\subsection{Phylogenetic structure of HFL communities}

To investigate the composition of the different HFL communities and their (dis)similarities, we conducted phylogenetic beta-diversity analyses using UniFrac distances (Lozupone and Knight, 2005). Similar to HFL sequence distributions, phylogenetic structures of HFL communities were significantly different between water masses (UniFrac weighted significance test; $p \leq 0.012$ ) but not between stations. Likewise, when applying weighted UniFrac metrics to jackknifed cluster analysis, we observed a significant relationship between HFL community compositions and water mass category, indicating that HFL communities collected from surface, SCM and SCM $b$ waters were distinct from each other (Fig. 2a). The same relative depth-dependent similarities in HFL community composition were recovered using principal coordinate analysis (PCoA; Fig. 2b) of UniFrac weighted distances. Furthermore, HFL communities clustered by water mass in both unweighted UniFrac and Bray-Curtis distance metrics (Figs. S3A and S3B, respectively), which indicates that the rarer OTUs followed the same trends as the more abundant OTUs. Altogether, these results indicate a clear water mass segregation in the composition of HFL communities in the Beaufort Sea, with distinct assemblages occurring in the surface, SCM and SCM $b$ samples.

To determine if the water mass signal could be found at finer scales within main HFL lineages, we next deconstructed the weighted UniFrac cluster analysis by HFL taxonomic 


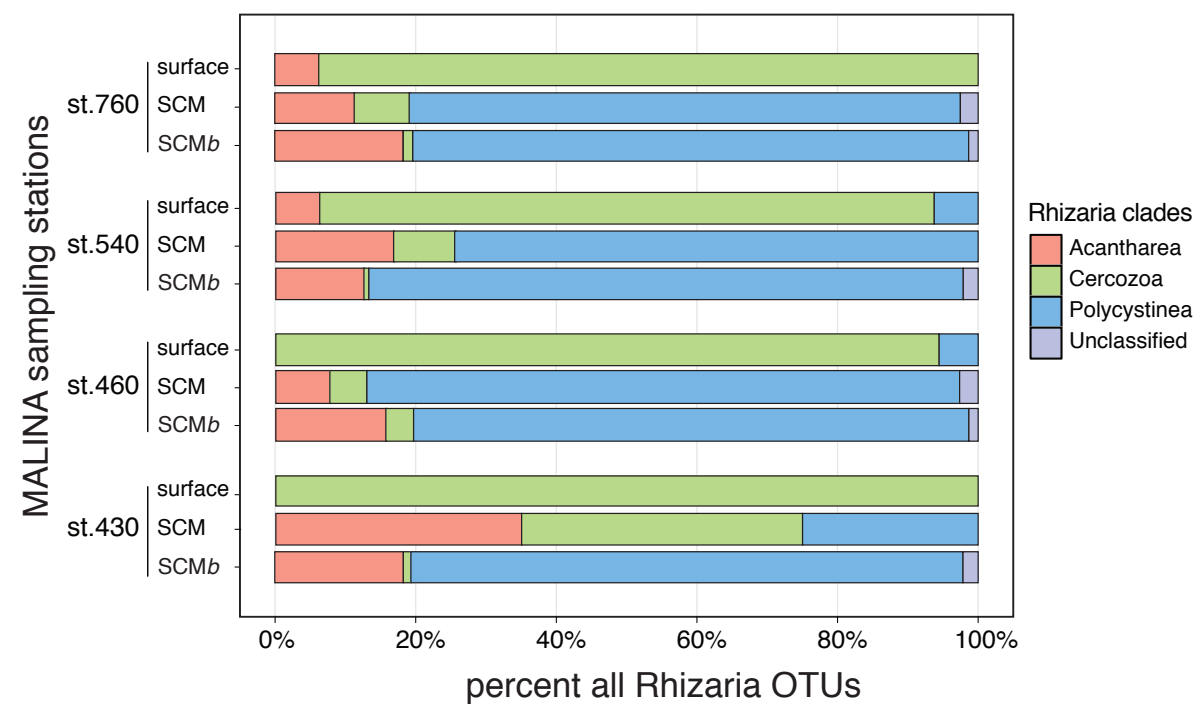

Fig. 3. Overall Rhizaria OTU distributions across Beaufort Sea samples. OTUs (clustered at $\geq 98 \%$ sequence identity) were taxonomically classified using an in-house curated sequence database based on NCBI taxonomy. The distributions of each sample in distinct Rhizaria clades are displayed according to the color legend.

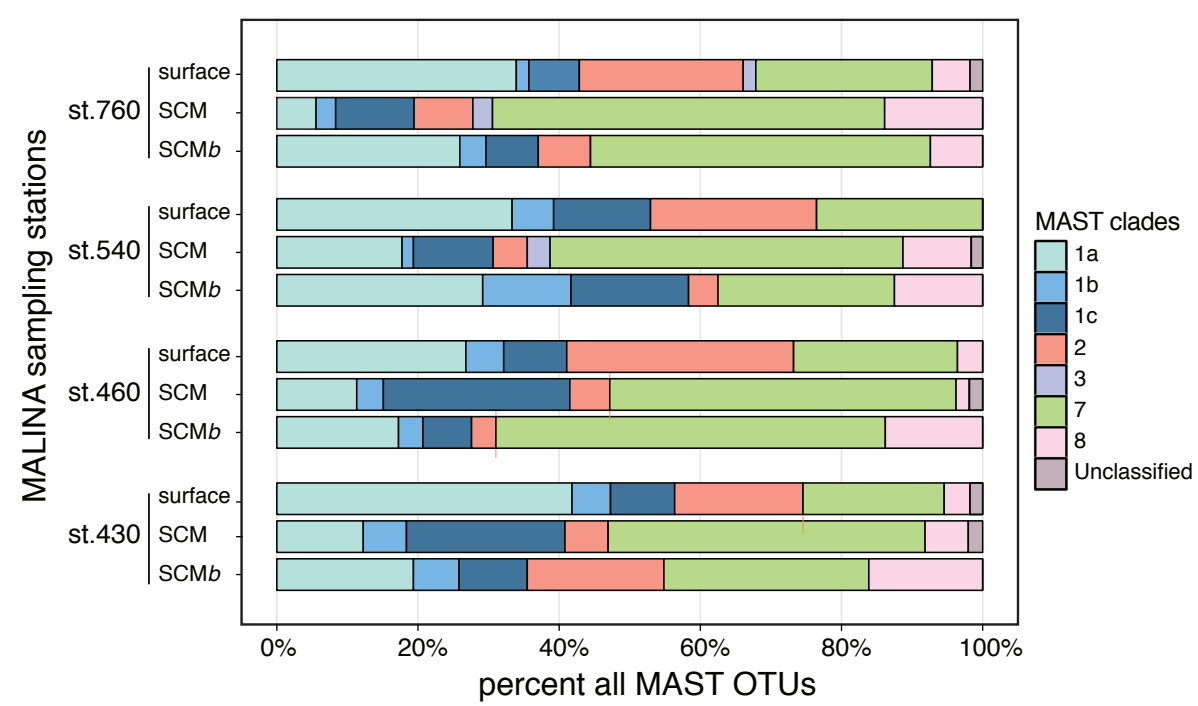

Fig. 4. Overall MAST OTU distributions across Beaufort Sea samples. OTUs (clustered at $\geq 98 \%$ sequence identity) were taxonomically classified using an in-house curated sequence database based on NCBI taxonomy. The distributions of each sample in distinct MAST subclades are displayed according to the color legend.

groups (Fig. S4). The clustering patterns were conserved overall for most major HFL clades, with the exception of the choanoflagellate and Telonemia lineages. Picozoa communities from surface samples were globally more similar to each other than Picozoa from deeper samples (i.e., SCM and SCM $b$ ). Rhizaria and MASTs were the HFL lineages with the most clearly depth-influenced composition. Within the Rhizaria, Cercozoa OTUs occurred at the surface, whereas deeper communities were mainly composed of Polycystinea OTUs (Fig. 3). In addition, the various com- munities of MASTs perfectly clustered based on their water mass of origin (Fig. S4), indicating MASTs were specific to the depth categories we sampled, and were good water mass biomarkers. Within the two exceptional lineages that did not follow water mass distributions, Telonemia communities followed station location, whereas choanoflagellates did not trend with either water mass or station. 


\subsection{MAST subclade distribution using a focused phylogenetic approach}

Because of the strong water mass signal that structured their community, at the phylogenetic level (i.e., UniFrac distances), we next focused on the distributions of the different MAST clades across depths, as well as among stations. Our taxonomic classifications assigned OTUs to eight previously delineated MAST clades: MAST 1, 2, 3, 7, 8 and unclassified MASTs. MAST-1 subclades (1a, 1b and 1c), MAST-2 and MAST-7 were the most abundant in terms of OTU numbers, indicating they were the most diverse (Fig. 4). Overall water mass influence on MAST diversity was at the clade and subclade levels (Fig. 4). Using OTU distributions, we found that the MAST-1a communities, which were the most diverse of the MAST- 1 subclades, were more diverse in surface waters and less diverse at the SCM. In contrast, OTUs classified as MAST-1c were more diverse at the SCM compared to surface or deeper waters. Generally, MAST-2 OTUs were more abundant in surface waters while MAST-7 OTUs were more abundant in SCM and $\mathrm{SCM} b$ waters. We next investigated MAST taxonomic distribution in the water masses at greater taxonomic resolution, with the goal of detecting patterns potentially missed by OTU analysis. We used a phylogenetic placement approach (Berger and Stamatakis, 2011; Matsen et al., 2010; Monier et al., 2008) to classify the MAST-1 reads. We chose this MAST clade as a case study because of the availability of reference sequences that are needed to produce a reference phylogeny with a strong phylogenetic signal. The reference tree (Fig. 5, left phylogram) shows clear distinctions between four MAST-1 subclades, all with high bootstrap support. Next, to gain semi-quantitative information, we mapped the reads classified as MAST-1 (not the OTU numbers) onto the MAST-1 reference tree. This phylogenetic mapping revealed two patterns within the MAST-1a and MAST-1c subclades. First, although MAST-1a had greater diversity in surface waters, numbers were dominated by a single group; furthermore, a high number of reads was also detected at the SCM $b$. Second, concordantly with MAST-1c diversity distribution, total and relative reads were the highest at the SCM, confirming a water mass selectivity of MAST-1 (Fig. 5, right cladogram).

\section{Discussion}

Here we provided a comprehensive survey of HFL communities using high-throughput sequencing in a stratified upper water column. Our study highlighted the partitioning of HFL assemblages by taxa at all levels, showing evidence of environmental selection over relatively small vertical spatial scales. When using phylogenetic beta-diversity distance metrics, with and without relative abundance information, the water mass taxon distribution remained robust.

The separation of taxa was evident at all taxonomic levels within the major recognized eukaryotic groupings (Adl et al., 2012). The separation within the Rhizaria, which includes three morphologically and functionally diverse lineages, Foraminifera, Cercozoa and Radiolaria (Burki et al., 2010; Cavalier-Smith, 2003), was particularly striking. Surface Rhizaria (Fig. S4) reads and OTU numbers were mainly in the Cercozoa (Fig. 3) with matches to taxa previously reported from Arctic surface waters (Lovejoy and Potvin, 2011; Lovejoy et al., 2006) including Cryothecomonas. Indeed, Thaler and Lovejoy (2012) used Cryothecomonas fluorescence in situ hybridization (FISH) to map its distribution across the Canadian Arctic and found it exclusively in surface waters; their analysis pointed to Cryothecomonas being closely associated with sea ice. Another recent study of sea ice from the Beaufort Sea, using the same high-throughput tag sequencing approach reported here, found that Cryothecomonas was a major contributor to the sea ice communities (Comeau et al., 2013). The offshore surface waters of the Malina study region were particularly impacted by ice (Matsuoka et al., 2012), consistent with the occurrence of Cryothecomonas. On the other hand, Radiolarians, especially Acantharea and Polycystinea sequences dominated the HFL assemblages of the SCM and $\mathrm{SCM} b$ (Fig. 3), as was earlier reported from cloning and sequencing studies in the Canada Basin and Amundsen Gulf (Lovejoy and Potvin, 2011; Lovejoy et al., 2006; Terrado et al., 2009). Nearly identical sequences have been reported from deep Pacific lowoxygen waters, and their occurrence in Pacific origin BSWW and BSSW has been rather constant across years and regions of the Canadian Arctic (Lovejoy and Potvin, 2011). It has long been stated that Radiolaria follow species-specific depth distributions (Russell, 1927), and we found greater diversity and abundance of Radiolaria in the SCM and SCM $b$. They were likely the dominant HFL within and below the SCM, preying both on bacteria and other flagellates (Matsuoka et al., 2007). Additional temporal and geographic data may uncover more species-specific ecological information, and eventually Radiolaria might be a good marker to detect the origin of upwelled surface waters. Along these same lines, a deeper understanding on the molecular diversity of this group would be useful for monitoring pulses of warm Atlantic waters entering the Arctic Ocean (Bjorklund et al., 2012).

While Cercozoa were common, in surface waters, MAST and Telonemia reads dominated HFL assemblages, both at the diversity and relative abundance levels (Fig. 1c). All of the MAST clades reported here (Fig. 4) have been previously recovered in clone libraries from the Beaufort and other Arctic seas (Lovejoy and Potvin, 2011; Lovejoy et al., 2006; Terrado et al., 2009; 2011), although it is intriguing that none was found under perennially ice-covered waters near the North Pole (Bachy et al., 2011). Previous reports have shown that different MAST clades may be segregated across spatial scales, which might be due to different prey affinities and availability (Lin et al., 2012; Piwosz and Pernthaler, 2010). Using pyrosequencing, Logares et al. (2012) reported differences in MAST assemblages, at the phylogenetic level, 


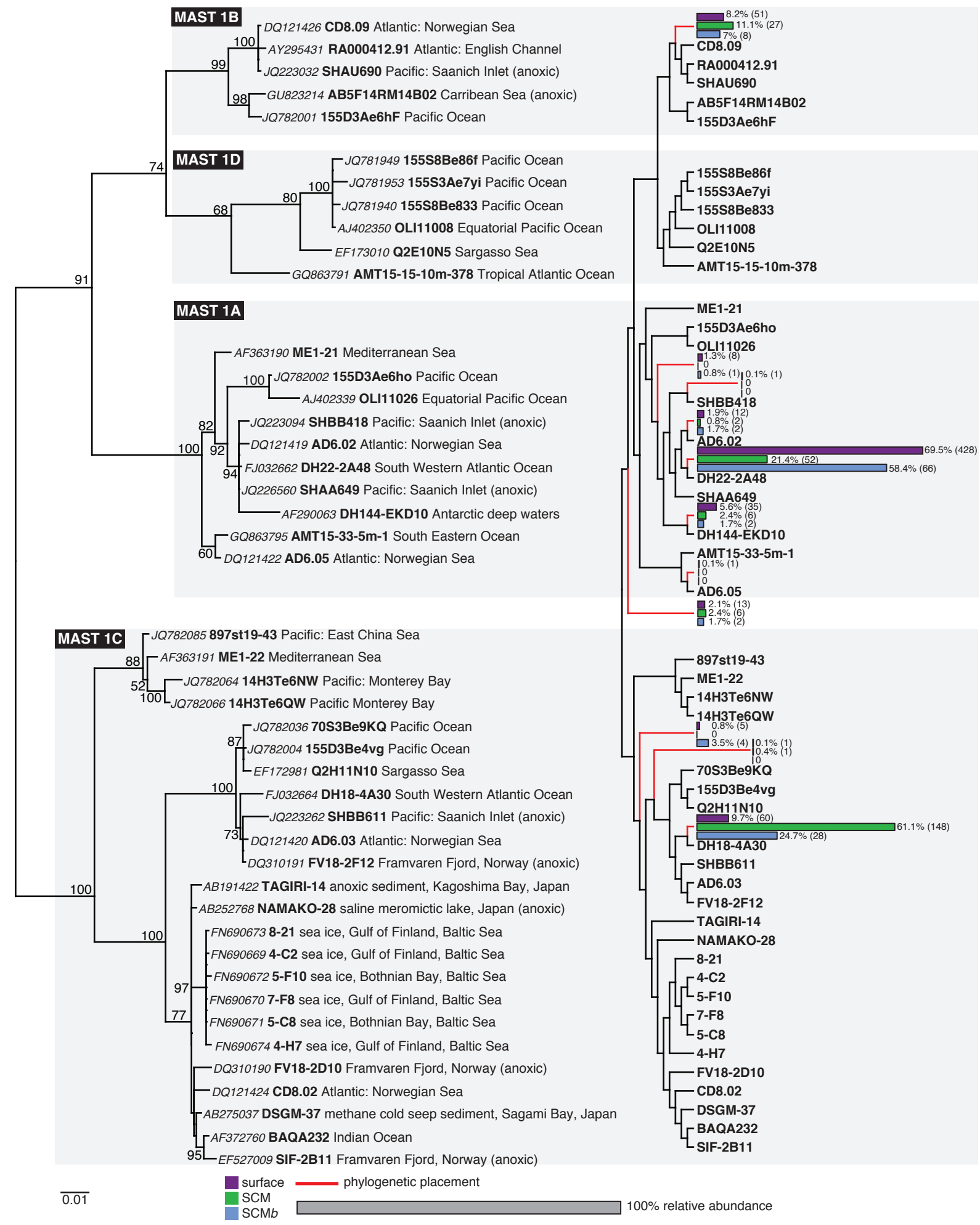

Fig. 5. Phylogenetic mapping of MAST-1 reads from the Beaufort Sea. MAST-1 reference phylogenetic tree (right phylogram) was reconstructed using maximum-likelihood, and node statistical supports were computed using 1000 rapid bootstrap replicates using RAxML. Reads classified as MAST-1 were mapped onto the MAST-1 reference tree using RAxML evolutionary placement algorithm (left cladogram). Phylogenetic placements are indicated by red branches. Distributions of phylogenetic placements are indicated by color bars (Purple, green and blue bars represent surface, SCM and SCM $b$ depths, respectively). First number corresponds to percent of total depth and second number is total number of a given depth mapped. 
between deep chlorophyll maximum and surface samples from European coastal waters, from a variety of sampling sites. We found significant partitioning of MAST communities down the water column (Fig. 5; Fig. S4), but not among sampling sites. The lack of geographical patterns could be due to the more limited area we sampled (i.e., the coastal Beaufort Sea) compared to the study from Logares et al. (2012), which included the coastal Mediterranean Sea and English Channel. Extending our survey of HFL communities beyond the Beaufort Sea may reveal geographical differences in Arctic MAST communities.

MASTs belonging to clades 1, 2, 3 and 7 are thought to be ubiquitous in Arctic waters (Lovejoy et al., 2006), and previous reports suggested that their distributions are shaped by prey affinities and availability (e.g., Lin et al., 2012). Comeau et al. (2013) recently noted that MASTs tended to co-occur with diatoms in sea ice. Similarly, in a late-winter-spring study, MAST-1a and 1c were absent from clone libraries constructed based on the rRNA template (Terrado et al., 2011), and these authors suggested that this may have been linked to low concentrations of bacteria available for grazing. Comeau et al. (2011) reported a decrease in the proportion of MAST sequences in the Amundsen Gulf SCM following the accelerated seasonal ice-cover loss since 2007.

Overall, MASTs are not only taxonomically diverse but also likely occupy a number of ecological roles. Our analysis of MAST communities showed vertical specificity at the phylogenetic level (Fig. S4), likely indicating that prey preference and availability shape these communities. Surface MAST communities differed phylogenetically from those in deeper water masses. Specifically, MAST-1a and -2 were overall more diverse in all surface samples; this higher diversity in MAST-1a and -2 phylotypes appears as a characteristic of surface waters from the Beaufort Sea.

The use of a pyrosequencing approach enabled us to recover many more sequences than reported from clone libraries. Despite this, in our taxonomic survey we did not recover reads classified as MAST-4 in any of the sampled communities. Although the MAST-4 clade is one of the most widely distributed and abundant MAST clades in most oceans, it is generally absent from polar waters (Massana et al., 2006; Rodríguez-Martínez et al., 2009), and the few records of its presence have been related to Pacific water inflows (Comeau et al., 2011; Lovejoy and Potvin, 2011). MAST-4 cells were first reported to feed on heterotrophic bacteria (Massana et al., 2006) but more recently, they have been shown to prey on the picocyanobacteria Synechoccocus (Lin et al., 2012). The Arctic Ocean is noteworthy for lacking picocyanobacteria (Tremblay et al., 2009; Waleron et al., 2006), a feature shared by the cold waters around Antarctica (Ghiglione and Murray, 2011; Wilkins et al., 2012). We hypothesize that the absence of MAST-4 from polar waters could be linked to the absence of its cyanobacterial prey.

MAST-3 is reported to be globally the most abundant of the MAST clades (Logares et al., 2011) and MAST-3 se-

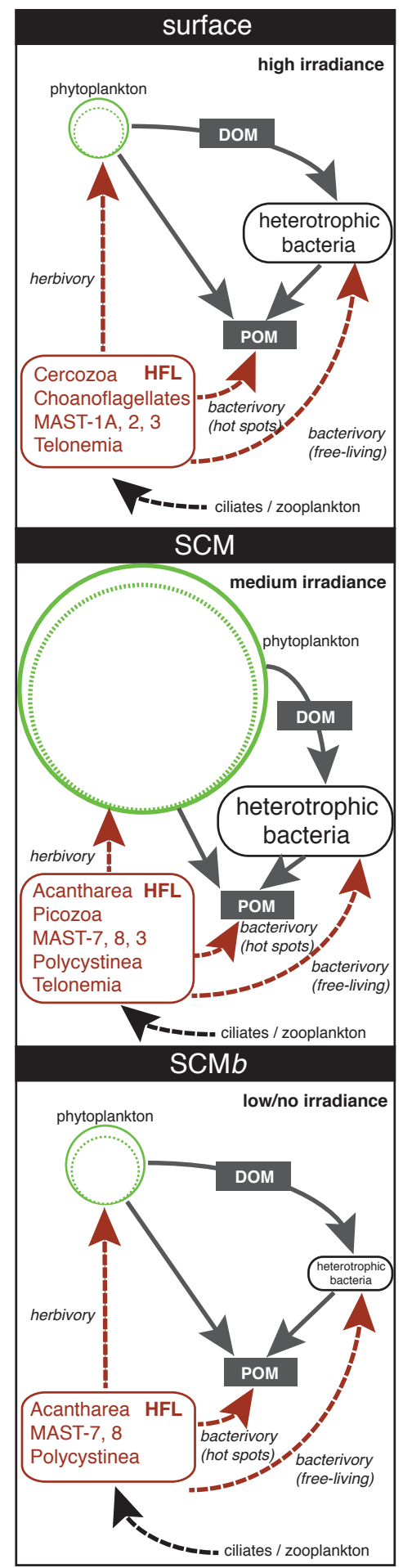

Fig. 6. Schematic of the trophic networks in the upper Arctic Ocean, in light of HFL taxonomic information within the upper water column: surface, SCM and SCM $b$. Bacteria counts and phytoplankton $(\operatorname{chl} a)$ are scaled to actual values available at http://malina.obs-vlfr. fr. For phytoplankton, inner and outer circles represent small and total fractions from extracted chl $a$ values, respectively. 
quences have been previously reported from this same region of the Arctic (Lovejoy et al., 2006; Terrado et al., 2011). However, we found relatively few MAST-3 sequences in this study and their occurrence was sporadic, being found only in the surface and SCM depths of two stations. Recently, Gómez et al. (2011) suggested that MAST-3 cells may be parasites of diatoms, because of $18 \mathrm{~S}$ rRNA gene phylogenetic affinity with Solenicola setigera, which is a well known diatom epibiont. However, the ecology of the clade is still largely speculative. For example, Terrado et al. (2011) cloned and sequenced 18S rRNA from surface and BSSW samples collected from mid-March to mid-May in Amundsen Gulf, using both DNA and RNA as templates. They found that MAST-3 was most common in the RNA template libraries in mid-March, prior to diatoms becoming abundant.

Telonemia, was only recently described and, although accepted as a phylum-level taxon (Shalchian-Tabrizi et al., 2007), its taxonomic affinities to other eukaryotes remains unresolved. These phagotrophic predators appear to be widely distributed in marine environments (Bråte et al., 2010). Microscopy-based and molecular-based surveys in the Arctic have reported Telonemia from Arctic surface waters (Bråte et al., 2010; Lovejoy et al., 2006; 2002; Terrado et al., 2011; Vørs, 1993), as well as sea ice (Bachy et al., 2011; Comeau et al., 2013; Ikävalko and Gradinger, 1997; Majaneva et al., 2011; Różańska et al., 2008; Sazhin et al., 2004; Werner et al., 2007). Telonemia could well be specialists since they are most often found in surface waters, and, for example, they were absent from deeper Western North Atlantic waters (Countway et al., 2007) as well as winter mesopelagic waters (150-200 m) in the Beaufort Sea (Terrado et al., 2009). We found that both Telonemia reads and OTUs were significantly greater in surface waters (Table S3); however, we did not detect any depth effect on Telonemia diversity, but in contrast to the other groups, local scale geographical influence was noted (Fig. S4). An earlier study suggested that there may be at least one Arctic restricted clade of Telonemia (Shalchian-Tabrizi et al., 2007), but this was later reported to be an artefact caused by undersampling (Bråte et al., 2010). The uniformity of very closely related phylotypes occurring sporadically over different geographic regions suggest that Telonemia may be able to survive long distance transport and then 'bloom' under precise conditions.

Sequences from Picozoa, previously known as "biliphyte" or "picobiliphyte", are commonly retrieved in the Arctic Ocean (Comeau et al., 2011; Hamilton et al., 2008; Not et al., 2007; Terrado et al., 2011). The term picobiliphyte was first used to describe this phylum-level taxon of uncertain phylogenetic affinities. The first sequences belonging to "biliphytes" were retrieved from samples that had been prefiltered through a $3 \mu \mathrm{m}$ filter (picoplanktonic size) and an $18 \mathrm{~S}$ rRNA specific FISH probe revealed phycobilin-like fluorescence in many of the FISH positive cells (Not et al., 2007). A subsequent review of related sequences from additional sites suggested that they were not uniformly pico-sized and were referred to then as "biliphytes" (Cuvelier et al., 2008). A recent study based on single-cell genome fragments failed to detect any plastid-related genes, implying they were strict phagotrophs (Yoon et al., 2011). The phylogenetic position based on multiple genes (Yoon et al., 2011) put them outside of any known photosynthetic groups (Adl et al., 2012). Recently, taxonomic diagnosis of an isolate, Picomonas judraskeda, showed that the lineage truly lacks a plastid, and it has been placed into the new eukaryotic phylum, Picozoa (Seenivasan et al., 2013). The phycobilin-like fluorescence reported earlier in FISH labeled cell may be due to ingested cyanobacterial prey (Kim et al., 2011). However, the paucity of cyanobacteria in the Arctic Ocean (Waleron et al., 2006) and the colloidal feeding mechanism described by Seenivasan et al. (2013) suggest that Picozoa cells in the Arctic Ocean most likely subsist on transparent exopolymer substrates, which are often abundant in Arctic waters (Riedel et al., 2006).

Within the HFL community, the choanoflagellates did not segregate by depth or station (Fig. S4). Choanoflagellates are spherical or ovoid cells with a funnel-shaped collar of microvilli surrounding a unique flagellum (King et al., 2009). The use of molecular markers has shown that there is an emerging diversity based on environmental surveys (Del Campo and Massana, 2011) as well as a cryptic diversity within described species (Stoupin et al., 2012). These organisms feed on small prey ( $<1 \mu \mathrm{m}$; Marchant and Scott, 1993), creating a current with their flagellum to drive algal and bacterial preys to the collar of microvilli that acts as a filter (Kiørboe, 2011). Choanoflagellates are morphologically very diverse, and include both single cells and larger colonies, and they could well specialize on particular prey and also be prey to larger heterotrophs. Although they are often found in the Arctic Ocean and other waters, they are rarely abundant.

\section{HFL in a dynamic Arctic}

Until recently, the cold, perennially ice-covered Arctic Ocean was considered a stable and predictable environment where food webs were short, with nutrient-triggered diatomdominated phytoplankton blooms following ice melt. These diatom blooms supported large zooplankton populations at the base of the food web. This view gives rise to a basic nutrient-phytoplankton-zooplankton-detritus (NPZD) type food web model that is widely used in ecosystem studies and often forms the base of the biological component of global climate models (Poulin and Franks, 2010). The simple NPZD model in the Arctic ignores the contribution of microbial cells, such as bacteria, archaea, small phytoflagellates and heterotrophic or parasitic protists, that persist throughout the year (Galand et al., 2009a, b; Terrado et al., 2008). A corollary of the phylogenetic selection and diversity of HFL communities observed here draws a picture of further complexity in the transfer of carbon in microbial food webs. 
Figure 6 illustrates, at relatively short vertical scales (Surface, SCM and $\mathrm{SCM} b$ ), the flow of carbon through HFL communities. The upper mixed layer in the Arctic remains depleted in nitrate through much of the year, driving the formation of a SCM at the pycnocline created by BSSW that becomes closely associated with the nitracline (Martin et al., 2010). The input of nitrate and silicate from the BSSW drives much of the primary production in the Beaufort Sea region, and the lack of nutrients in the surface waters limits productivity, while low light levels impede photosynthesis below the SCM. Polar regions are currently warming more rapidly than other regions of the planet, resulting in a freshening of the Arctic from terrestrial (permafrost) melt, increased discharge of large rivers and melting multiyear ice, impacting the hydrography of the region (McLaughlin et al., 2005). The loss of summer ice cover has also been linked to changes in the size structure of the phytoplankton communities ( $\mathrm{Li}$ et al., 2009) and changes in major microbial species and species groups (Comeau et al., 2011).

\section{Future directions}

Recent studies using molecular markers have shown that the species composition of small phytoplankton varies both seasonally and by depth (Giovannoni and Vergin, 2012; Treusch et al., 2011), implying strong environmental selection of particular phylotypes. In contrast to photosynthetic microbes, including phytoplankton, which are vertically stratified due to a strong selection by easily identifiable abiotic factors such as irradiance levels or nutrient availability (Demir-Hilton et al., 2011; Johnson et al., 2006), little is known about the drivers that structure HFL communities within the water column.

Prey type, size and availability within the water column likely drives selection for particular HFL taxa. The HFL taxa also likely compete with mixotrophic grazers, and overall the complexity of microbial eukaryotic communities is underappreciated. Additional studies aimed at revealing predatorprey interactions and detection of significant co-occurrences using a network analysis approach linking eukaryotic, bacterial and archaeal diversities are needed. Ecological studies integrating network analyses have so far focused on a single domain of life, specifically bacterial OTU co-occurrences (Barberán et al., 2011; Chaffron et al., 2010). The use of such approaches demands a large number of samples in order to identify significant statistical relationships (Barberán et al., 2011); given the relatively low number of samples in our study, this kind of analysis is out of the scope of this paper. Earlier clone library results (Lovejoy and Potvin, 2011) showed that the physically stable Beaufort Sea water column (Carmack, 2007) harbors distinct eukaryotic communities within different water masses. Our results from high-throughput sequencing enabled us to explore taxonomic trends of HFL with much greater detail; a comparison of the nutrient-depleted surface mixed layer, the SCM and be- low the SCM, highlighted very different grazer communities, suggesting differences in the prey characteristics within the three water masses. The dramatic seasonality in the Arctic means that microbial communities may rapidly shift due to both succession (Terrado et al., 2008) and water mass movements (Terrado et al., 2011), and future studies will likely unveil additional factors favoring the prevalence of HFL taxa.

\section{Supplementary material related to this article is available online at: http://www.biogeosciences.net/10/ 4273/2013/bg-10-4273-2013-supplement.pdf.}

Acknowledgements. We are grateful to the crew and captain of the Canadian research icebreaker CCGS Amundsen. This study was conducted as part of the Malina Scientific Program led by Marcel Babin and funded by ANR (Agence Nationale de la Recherche), INSU-CNRS (Institut national des sciences de l'univers - Centre national de la recherche scientifique), CNES (Centre national d'études spatiales) and ESA (European Space Agency). Computing support from CLUMEQ/Compute Canada was appreciated. Funding for this analysis and ship logistics was from a Natural Science and Engineering Council (NSERC) of Canada and a discovery grant to $\mathrm{CL}$, and is a contribution to ArcticNet. A. Monier is funded through the Canadian Excellence Research Chair in remote sensing of Canada's new Arctic frontier awarded to Marcel Babin.

Edited by: G. Herndl

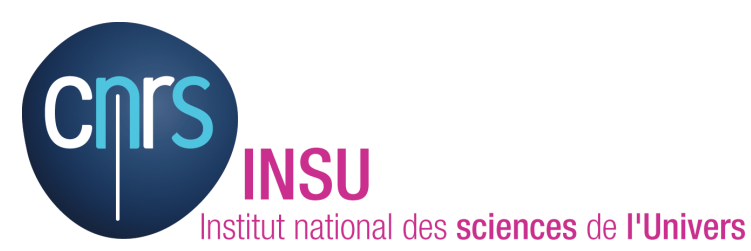

The publication of this article is financed by CNRS-INSU.

\section{References}

Adl, S. M., Simpson, A. G. B., Lane, C. E., Lukeš, J., Bass, D., Bowser, S. S., Brown, M. W., Burki, F., Dunthorn, M., Hampl, V., Heiss, A., Hoppenrath, M., Lara, E., le Gall, L., Lynn, D. H., McManus, H., Mitchell, E. A. D., Mozley-Stanridge, S. E., Parfrey, L. W., Pawlowski, J., Rueckert, S., Shadwick, L., Schoch, C. L., Smirnov, A., and Spiegel, F. W.: The Revised Classification of Eukaryotes, J. Eukaryotic. Microbiol., 59, 429-514, doi:10.1111/j.1550-7408.2012.00644.x, 2012.

Altschul, S. F., Madden, T. L., Schäffer, A. A., Zhang, J., Zhang, Z., Miller, W., and Lipman, D. J.: Gapped BLAST and PSI-BLAST: a new generation of protein database search programs, Nucleic. Acids. Res., 25, 3389-3402, doi:10.1093/nar/25.17.3389, 1997.

Azam, F. and Malfatti, F.: Microbial structuring of marine ecosystems, Nat. Rev. Microbiol., 5, 782-791, doi:10.1038/nrmicro1747, 2007. 
Bachy, C., López-García, P., Vereshchaka, A., and Moreira, D.: Diversity and vertical distribution of microbial eukaryotes in the snow, sea ice and seawater near the north pole at the end of the polar night, Front. Microbiol., 2, 106, doi:10.3389/fmicb.2011.00106, 2011.

Barberán, A., Bates, S. T., Casamayor, E. O., and Fierer, N.: Using network analysis to explore co-occurrence patterns in soil microbial communities, ISME J., 6, 343-351, doi:10.1038/ismej.2011.119, 2011.

Berger, S. A. and Stamatakis, A.: Aligning short reads to reference alignments and trees, Bioinformatics, 27, 2068-2075, doi:10.1093/bioinformatics/btr320, 2011.

Bjorklund, K. R., Kruglikova, S. B., and Anderson, O. R.: Modern incursions of tropical Radiolaria into the Arctic Ocean, J. Micropalaeontol., 31, 139-158, doi:10.1144/0262-821X11-030, 2012.

Bråte, J., Klaveness, D., Rygh, T., Jakobsen, K. S., and ShalchianTabrizi, K.: Telonemia-specific environmental 18S rDNA PCR reveals unknown diversity and multiple marine-freshwater colonizations, BMC Microbiol., 10, 168, doi:10.1186/1471-2180-10168, 2010.

Burki, F., Kudryavtsev, A., Matz, M. V., Aglyamova, G. V., Bulman, S., Fiers, M., Keeling, P. J., and Pawlowski, J.: Evolution of Rhizaria: new insights from phylogenomic analysis of uncultivated protists, BMC Evol. Biol., 10, 377, doi:10.1186/14712148-10-377, 2010.

Carmack, E. C.: The alpha/beta ocean distinction: A perspective on freshwater fluxes, convection, nutrients and productivity in high-latitude seas, Deep-Sea Res. Pt. II, 54, 2578-2598, doi:10.1016/j.dsr2.2007.08.018, 2007

Carmack, E. C. and Macdonald, R. W.: Oceanography of the Canadian shelf of the Beaufort Sea: a setting for marine life, Arctic, 55, 29-45, 2002.

Cavalier-Smith, T.: Protist phylogeny and the high-level classification of Protozoa, Europ. J. Protistol., 39, 338-348, doi:10.1078/0932-4739-00002, 2003.

Chaffron, S., Rehrauer, H., Pernthaler, J., and Mering, von, C.: A global network of coexisting microbes from environmental and whole-genome sequence data, Genome Res., 20, 947-959, doi:10.1101/gr.104521.109, 2010.

Comeau, A. M., Li, W. K. W., Tremblay, J.-É., Carmack, E. C., and Lovejoy, C.: Arctic Ocean Microbial Community Structure before and after the 2007 Record Sea Ice Minimum, PLoS ONE, 6, e27492, doi:10.1371/journal.pone.0027492, 2011.

Comeau, A. M., Philippe, B., Thaler, M., Gosselin, M., Poulin, M., and Lovejoy, C.: Protists in Arctic drift and land-fast sea ice, J. Phycol., 49, 229-240, doi:10.1111/jpy.12026, 2013.

Countway, P. D., Gast, R. J., Dennett, M. R., Savai, P., Rose, J. M., and Caron, D. A.: Distinct protistan assemblages characterize the euphotic zone and deep sea $(2500 \mathrm{~m})$ of the western North Atlantic (Sargasso Sea and Gulf Stream), Environ. Microbiol., 9, 1219-1232, doi:10.1111/j.1462-2920.2007.01243.x, 2007.

Cuvelier, M. L., Ortiz, A., Kim, E., Moehlig, H., Richardson, D. E., Heidelberg, J. F., Archibald, J. M., and Worden, A. Z.: Widespread distribution of a unique marine protistan lineage, Environ. Microbiol., 10, 1621-1634, doi:10.1111/j.14622920.2008.01580.x, 2008.

Del Campo, J. and Massana, R.: Emerging Diversity within Chrysophytes, Choanoflagellates and Bicosoecids Based on Molecular
Surveys, Protist, 2011.

Demir-Hilton, E., Sudek, S., Cuvelier, M. L., Gentemann, C. L., Zehr, J. P., and Worden, A. Z.: Global distribution patterns of distinct clades of the photosynthetic picoeukaryote Ostreococcus, ISME J, 5, 1095-1107, doi:10.1038/ismej.2010.209, 2011.

Edgar, R. C., Haas, B. J., Clemente, J. C., Quince, C., and Knight, R.: UCHIME improves sensitivity and speed of chimera detection, Bioinformatics, 27, 2194-2200, doi:10.1093/bioinformatics/btr381, 2011.

Forest, A., Babin, M., Stemmann, L., Picheral, M., Sampei, M., Fortier, L., Gratton, Y., Bélanger, S., Devred, E., Sahlin, J., Doxaran, D., Joux, F., Ortega-Retuerta, E., Martín, J., Jeffrey, W. H., Gasser, B., and Carlos Miquel, J.: Ecosystem function and particle flux dynamics across the Mackenzie Shelf (Beaufort Sea, Arctic Ocean): an integrative analysis of spatial variability and biophysical forcings, Biogeosciences, 10, 2833-2866, doi:10.5194/bg-10-2833-2013, 2013.

Galand, P. E., Casamayor, E. O., Kirchman, D. L., and Lovejoy, C.: Ecology of the rare microbial biosphere of the Arctic Ocean, Proc. Natl. Acad. Sci. USA, 106, 22427-22432, doi:10.1073/pnas.0908284106, 2009a.

Galand, P. E., Potvin, M., Casamayor, E. O., and Lovejoy C.: Hydrography shapes bacterial biogeography of the deep Arctic Ocean, ISME J., 4, 564-576, doi:10.1038/ismej.2009.134, 2009b.

Ghiglione, J. F. and Murray, A. E.: Pronounced summer to winter differences and higher wintertime richness in coastal Antarctic marine bacterioplankton, Environ. Microbiol., 14, 617-629, doi:10.1111/j.1462-2920.2011.02601.x, 2011.

Giovannoni, S. J. and Vergin, K. L.: Seasonality in ocean microbial communities, Science, 335, 671-676, doi:10.1126/science.1198078, 2012.

Gómez, F., Moreira, D., Benzerara, K., and López-García, P.: Solenicola setigera is the first characterized member of the abundant and cosmopolitan uncultured marine stramenopile group MAST-3, Environ. Microbiol., 13, 193-202, doi:10.1111/j.14622920.2010.02320.x, 2011.

Gouy, M., Guindon, S., and Gascuel, O.: SeaView version 4: A multiplatform graphical user interface for sequence alignment and phylogenetic tree building, Mol. Biol. Evol., 27, 221-224, doi:10.1093/molbev/msp259, 2010.

Hamady, M., Lozupone, C., and Knight, R.: Fast UniFrac: facilitating high-throughput phylogenetic analyses of microbial communities including analysis of pyrosequencing and PhyloChip data, ISME J., 4, 17-27, doi:10.1038/ismej.2009.97, 2010.

Hamilton, A. K., Lovejoy, C., Galand, P. E., and Ingram, R. G.: Water masses and biogeography of picoeukaryote assemblages in a cold hydrographically complex system, Limnol. Oceanogr., 53, 922-935, 2008.

Hawlitschek, O., Hendrich, L., Espeland, M., Toussaint, E. F. A., Genner, M. J., and Balke, M.: Pleistocene climate change promoted rapid diversification of aquatic invertebrates in Southeast Australia, BMC Evol. Biol., 12, 142, doi:10.1186/1471-2148-12$142,2012$.

Ikävalko, J. and Gradinger, R.: Flagellates and heliozoans in the Greenland Sea ice studied alive using light microscopy, Polar Biol., 17, 473-481, doi:10.1007/s003000050145, 1997.

Jackson, J. M., Williams, W. J., and Carmack, E. C.: Winter sea-ice melt in the Canada Basin, Arctic Ocean, Geophys. Res. Lett., 39, 
L03603, doi:10.1029/2011GL050219, 2012.

Johnson, Z. I., Zinser, E. R., Coe, A., McNulty, N. P., Woodward, E. M. S., and Chisholm, S. W.: Niche partitioning among Prochlorococcus ecotypes along ocean-scale environmental gradients, Science, 311, 1737-1740, doi:10.1126/science.1118052, 2006.

Jones, S. E. and Lennon, J. T.: Dormancy contributes to the maintenance of microbial diversity, Proc Natl Acad Sci USA, 107, 5881-5886, doi:10.1073/pnas.0912765107, 2010.

Jürgens, K. and Massana, R.: Protist grazing on marine bacterioplankon, edited by: Kirchman, D. L., Microbial Ecology of the Oceans, second edition, John Wiley \& Sons, Inc., New York, USA, 383-441, 2008.

Kim, E., Harrison, J. W., Sudek, S., Jones, M. D. M., Wilcox, H. M., Richards, T. A., Worden, A. Z., and Archibald, J. M.: Newly identified and diverse plastid-bearing branch on the eukaryotic tree of life, Proc. Natl. Acad. Sci. USA, 108, 14961500, doi:10.1073/pnas.1013337108, 2011.

King, N., Young ,S. L., Abedin, M., Carr, M., and Leadbeater, B. S. C.: The choanoflagellates: heterotrophic nanoflagellates and sister group of the metazoa, Cold Spring Harb. Protoc., 4, doi:10.1101/pdb.emo116, 2009.

Kiørboe, T.: How zooplankton feed: mechanisms, traits and trade-offs, Biol. Rev., 86, 311-339, doi:10.1111/j.1469185X.2010.00148.x, 2011.

Li, W. K. W., McLaughlin, F. A., Lovejoy, C., and Carmack, E. C.: Smallest algae thrive as the Arctic Ocean freshens, Science, 326, p. 539, doi:10.1126/science.1179798, 2009.

Lin, Y.-C., Campbell, T., Chung, C.-C., Gong, G.-C., Chiang, K.P., and Worden, A. Z.: Distribution patterns and phylogeny of marine stramenopiles in the north pacific ocean, Appl. Environ. Microbiol., 78, 3387-3399, doi:10.1128/AEM.06952-11, 2012.

Logares, R., Audic, S., Santini, S., Pernice, M. C., de Vargas, C., and Massana, R.: Diversity patterns and activity of uncultured marine heterotrophic flagellates unveiled with pyrosequencing, ISME J, 6, 1823-1833, doi:10.1038/ismej.2012.36, 2012.

Lovejoy, C. and Potvin, M.: Microbial eukaryotic distribution in a dynamic Beaufort Sea and the Arctic Ocean, J. Plank. Res., 33, 431-444, doi:10.1093/plankt/fbq124, 2011.

Lovejoy, C., Legendre, L., Martineau, M.-J., Bâcle, J., and von Quillfeldt, C. H.: Distribution of phytoplankton and other protists in the North Water, Deep-Sea Res. Pt. II, 49, 5027-5047, doi:10.1016/S0967-0645(02)00176-5, 2002.

Lovejoy, C., Massana, R., and Pedrós-Alió, C.: Diversity and distribution of marine microbial eukaryotes in the Arctic Ocean and adjacent seas, Appl. Environ. Microbiol., 72, 3085-3095, doi:10.1128/AEM.72.5.3085-3095.2006, 2006.

Lovejoy, C., Vincent, W. F., Bonilla, S., Roy, S., Martineau, M.-J., Terrado, R., Potvin, M., Massana, R., and Pedrós-Alió, C.: Distribution, phylogeny, and growth of cold-adapted picoprasinophytes in Arctic seas, J. Phycol., 43, 78-89, doi:10.1111/j.15298817.2006.00310.x, 2007.

Lozupone, C. and Knight, R.: UniFrac: a new phylogenetic method for comparing microbial communities, Appl. Environ. Microbiol., 71, 8228-8235, doi:10.1128/AEM.71.12.8228-8235.2005, 2005.

Majaneva, M., Rintala, J.-M., Piisilä, M., Fewer, D. P., and Blomster, J.: Comparison of wintertime eukaryotic community from sea ice and open water in the Baltic Sea, based on se- quencing of the 18S rRNA gene, Polar Biol., 35, 875-889, doi:10.1007/s00300-011-1132-9, 2011.

Marchant, H. J. and Scott, F. J.: Uptake of sub-micrometre particles and dissolved organic material by Antarctic choanoflagellates, Mar. Ecol. Prog. Ser., 92, 59-64, doi:10.3354/meps092059, 1993.

Martin, J., Tremblay, J. É., Gagnon, J., Tremblay, G., Lapoussière, A., Jose, C., Poulin, M., Gosselin, M., Gratton, Y., and Michel, C.: Prevalence, structure and properties of subsurface chlorophyll maxima in Canadian Arctic waters, Mar. Ecol. Prog. Ser., 412, 69-84, doi:10.3354/meps08666, 2010.

Massana, R.: Eukaryotic picoplankton in surface oceans, Annu. Rev. Microbiol., 65, 91-110, doi:10.1146/annurev-micro090110-102903, 2011.

Massana, R., Castresana, J., Balagué, V., Guillou, L., Romari, K., Groisillier, A., Valentin, K., and Pedrós-Alió, C.: Phylogenetic and Ecological Analysis of Novel Marine Stramenopiles, Appl. Environ. Microbiol., 70, 3528-3534, doi:10.1128/AEM.70.6.3528-3534.2004, 2004.

Massana, R., Terrado, R., Forn, I., Lovejoy, C., and Pedrós-Alió, C.: Distribution and abundance of uncultured heterotrophic flagellates in the world oceans, Environ. Microbiol., 8, 1515-1522, doi:10.1111/j.1462-2920.2006.01042.x, 2006.

Matsen, F. A., Kodner, R. B., and Armbrust, E. V.: pplacer: linear time maximum-likelihood and Bayesian phylogenetic placement of sequences onto a fixed reference tree, BMC Bioinformatics, 11, 538, doi:10.1186/1471-2105-11-538, 2010.

Matsuoka, A., Huot, Y., Shimada, K., Saitoh, S.-I., and Babin, M.: Bio-optical characteristics of the western Arctic Ocean: implications for ocean color algorithms, Can. J. Remote Sens., 33, 503-518, doi:10.5589/m07-059, 2007.

Matsuoka, A., Bricaud, A., Benner, R., Para, J., Sempéré, R., Prieur, L., Bélanger, S., and Babin, M.: Tracing the transport of colored dissolved organic matter in water masses of the Southern Beaufort Sea: relationship with hydrographic characteristics, Biogeosciences, 9, 925-940, doi:10.5194/bg-9-925-2012, 2012.

McLaughlin, F., Shimada, K., Carmack, E., Itoh, M., and Nishino, S.: The hydrography of the southern Canada Basin, 2002, Polar Biol., 28, 182-189, doi:10.1007/s00300-004-0701-6, 2005.

Monier, A., Claverie, J.-M., and Ogata, H.: Taxonomic distribution of large DNA viruses in the sea, Genome Biol., 9, R106, doi:10.1186/gb-2008-9-7-r106, 2008.

Not, F., Valentin, K., Romari, K., Lovejoy, C., Massana, R., Tobe, K., Vaulot, D., and Medlin, L. K.: Picobiliphytes: a marine picoplanktonic algal group with unknown affinities to other eukaryotes, Science, 315, 253-255, doi:10.1126/science.1136264, 2007.

Piwosz, K. and Pernthaler, J.: Seasonal population dynamics and trophic role of planktonic nanoflagellates in coastal surface waters of the Southern Baltic Sea, Environ. Microbiol., 12, 364 377, doi:10.1111/j.1462-2920.2009.02074.x, 2010.

Poulin, F. J. and Franks, P. J. S.: Size-structured planktonic ecosystems: constraints, controls and assembly instructions, J. Plankt. Res., 32, 1121-1130, doi:10.1093/plankt/fbp145, 2010.

Price, M. N., Dehal, P. S., and Arkin, A. P.: FastTree 2approximately maximum-likelihood trees for large alignments, PLoS ONE, 5, e9490, doi:10.1371/journal.pone.0009490, 2010.

Pruesse, E., Quast, C., Knittel, K., Fuchs, B. M., Ludwig, W., Peplies, J., and Gloeckner, F. O.: SILVA: a comprehensive on- 
line resource for quality checked and aligned ribosomal RNA sequence data compatible with ARB, Nucleic Acids Res, 35, 71887196, doi:10.1093/nar/gkm864, 2007.

Rainville, L., Lee, C. M., and Woodgate, R. A.: Impact of WindDriven Mixing in the Arctic Ocean, Oceanography, 24, 136-145, doi:10.5670/oceanog.2011.65, 2011.

Riedel, A., Michel, C., and Gosselin M.: Seasonal study of sea-ice exopolymeric substances on the Mackenzie shelf: implications for transport of sea-ice bacteria and algae, Aq. Microb. Ecol., 45, 195-206, doi:10.3354/ame045195, 2006.

Rodríguez-Martínez, R., Labrenz, M., del Campo, J., Forn, I., Jürgens, K., and Massana, R.: Distribution of the uncultured protist MAST-4 in the Indian Ocean, Drake Passage and Mediterranean Sea assessed by real-time quantitative PCR, Environ. Microbiol., 11, 397-408, doi:10.1111/j.1462-2920.2008.01779.x, 2009.

Różańska, M., Poulin, M., and Gosselin, M.: Protist entrapment in newly formed sea ice in the Coastal Arctic Ocean, J. Mar. Sys., 74, 887-901, doi:10.1016/j.jmarsys.2007.11.009, 2008.

Russell, F. S.: The vertical distribution of plankton in the sea, Biol. Rev., 2, 213-262, doi:10.1111/j.1469-185X.1927.tb00878.x, 1927.

Sazhin, A. F., Rat'kova, T. N., and Kosobokova, K. N.: Inhabitants of the White Sea coastal ice during the early spring period, Russ. Acad. Sci. Oceanol., 44, 82-89, 2004.

Schloss, P. D., Westcott, S. L., Ryabin, T., Hall, J. R., Hartmann, M., Hollister, E. B., Lesniewski, R. A., Oakley, B. B., Parks, D. H., Robinson, C. J., Sahl, J. W., Stres, B., Thallinger, G. G., Van Horn, D. J., and Weber, C. F.: Introducing mothur: open-source, platform-independent, community-supported software for describing and comparing microbial communities, Appl. Environ. Microbiol., 75, 7537-7541, doi:10.1128/AEM.01541-09, 2009.

Seenivasan, R., Sausen, N., Medlin, L. K., and Melkonian, M.: Picomonas judraskeda Gen. Et Sp. Nov.: The First Identified Member of the Picozoa Phylum Nov., a Widespread Group of Picoeukaryotes, Formerly Known as "Picobiliphytes", PLoS ONE, 8, e59565, doi:10.1371/journal.pone.0059565, 2013.

Shalchian-Tabrizi, K., Kauserud, H., Massana, R., Klaveness, D., and Jakobsen, K. S.: Analysis of environmental 18S ribosomal RNA sequences reveals unknown diversity of the cosmopolitan phylum Telonemia, Protist, 158, 173-180, doi:10.1016/j.protis.2006.10.003, 2007.

Sherr, E. B. and Sherr, B. F.: Bacterivory and herbivory - Key roles of phagotrophic protists in pelagic food webs, Microb. Ecol., 28, 223-235, doi:10.1007/BF00166812, 1994.

Sherr, E. B. and Sherr, B. F.: Capacity of herbivorous protists to control initiation and development of mass phytoplankton blooms, Aquat. Microb. Ecol., 57, 253-262, doi:10.3354/ame01358, 2009.

Sogin, M. L., Morrison, H. G., Huber, J. A., Mark Welch, D., Huse, S. M., Neal, P. R., Arrieta, J. M., and Herndl, G. J.: Microbial diversity in the deep sea and the underexplored "rare biosphere", Proc. Natl. Acad. Sci. USA, 103, 12115-12120, doi:10.1073/pnas.0605127103, 2006.

Stamatakis, A.: RAxML-VI-HPC: maximum likelihoodbased phylogenetic analyses with thousands of taxa and mixed models, Bioinformatics, 22, 2688-2690, doi:10.1093/bioinformatics/btl446, 2006.
Stoupin, D., Kiss, A. K., Arndt, H., Shatilovich, A. V., Gilichinsky, D. A., and Nitsche, F.: Cryptic diversity within the choanoflagellate morphospecies complex Codosiga botrytis - Phylogeny and morphology of ancient and modern isolates, Europ. J. Protistol., 48, 263-273, doi:10.1016/j.ejop.2012.01.004, 2012.

Terrado, R., Lovejoy, C., Massana, R., and Vincent, W. F.: Microbial food web responses to light and nutrients beneath the coastal Arctic Ocean sea ice during the winter-spring transition, J. Mar. Syst., 74, 964-977, doi:10.1016/j.jmarsys.2007.11.001, 2008.

Terrado, R., Vincent, W. F., and Lovejoy, C.: Mesopelagic protists: diversity and succession in a coastal Arctic ecosystem, Aquat. Microb. Ecol., 56, 25-40, doi:10.3354/ame01327, 2009.

Terrado, R., Medrinal, E., Dasilva, C., Thaler, M., Vincent, W. F., and Lovejoy, C.: Protist community composition during spring in an Arctic flaw lead polynya, Polar Biol., 34, 1901-1914, doi:10.1007/s00300-011-1039-5, 2011.

Thaler, M. and Lovejoy, C.: Distribution and diversity of a protist predator Cryothecomonas (Cercozoa) in Arctic marine waters, J. Eukaryot. Microbiol., 59, 291-299, doi:10.1111/j.15507408.2012.00631.x, 2012.

Tremblay, G., Belzile, C., Gosselin, M., Poulin, M., Roy, S., and Tremblay, J. É.: Late summer phytoplankton distribution along a $3500 \mathrm{~km}$ transect in Canadian Arctic waters: strong numerical dominance by picoeukaryotes, Aquat. Microb. Ecol., 54, 55-70, doi:10.3354/ame01257, 2009.

Treusch, A. H., Demir-Hilton, E., Vergin, K. L., Worden, A. Z., Carlson, C. A., Donatz, M. G., Burton, R. M., and Giovannoni, S. J.: Phytoplankton distribution patterns in the northwestern Sargasso Sea revealed by small subunit rRNA genes from plastids, ISME J., 6, 481-492, doi:10.1038/ismej.2011.117, 2011.

Tsubouchi, T., Bacon, S., Naveira Garabato, A. C., Aksenov, Y., Laxon, S. W., Fahrbach, E., Beszczynska-Möller, A., Hansen, E., Lee, C. M., and Ingvaldsen, R. B.: The Arctic Ocean in summer: A quasi-synoptic inverse estimate of boundary fluxes and water mass transformation, J. Geophys. Res., 117, C01024, doi:10.1029/2011JC007174, 2012.

Vørs, N.: Heterotrophic amoebae, flagellates and heliozoa from Arctic marine waters (North West Territories, Canada and West Greenland), Polar Biol., 13, 113-126, doi:10.1007/BF00238544, 1993.

Waleron, M., Waleron, K., Vincent, W. F., and Wilmotte, A.: Allochthonous inputs of riverine picocyanobacteria to coastal waters in the Arctic Ocean, FEMS Microbiol. Ecol., 59, 356-365, doi:10.1111/j.1574-6941.2006.00236.x, 2006.

Werner, I., Ikävalko, J., and Schünemann, H.: Sea-ice algae in Arctic pack ice during late winter, Polar Biol., 30, 1493-1504, doi:10.1007/s00300-007-0310-2, 2007.

Wickham, H.: ggplot2, Springer-Verlag New York Inc, 2009.

Wilkins, D., Lauro, F. M., Williams, T. J., Demaere, M. Z., Brown, M. V., Hoffman, J. M., Andrews-Pfannkoch, C., McQuaid, J. B., Riddle, M. J., Rintoul, S. R., and Cavicchioli, R.: Biogeographic partitioning of Southern Ocean microorganisms revealed by metagenomics, Environ. Microbiol., 15, 1462-2920, doi:10.1111/1462-2920.12035, 2012.

Yoon, H. S., Price, D. C., Stepanauskas, R., Rajah, V. D., Sieracki, M. E., Wilson, W. H., Yang, E. C., Duffy, S., and Bhattacharya, D.: Single-cell genomics reveals organismal interactions in uncultivated marine protists, Science, 332, 714-717, doi:10.1126/science.1203163, 2011. 